\title{
The Relationship between Sleeping Habits and Academic Performance among Medical Students in King Faisal University, Saudi Arabia
}

\author{
Abdulrahman Ahmad Al Naim¹, Abdulaziz Abdullah Al Ahmari², Mohammed Ahmed Al Omari ${ }^{3}$, \\ Sayed Ibrahim $\mathrm{Ali}^{4}$ \\ ${ }^{1,4}$ King Faisal University, College of Medicine, Saudi Arabia \\ ${ }^{2,3}$ Dammam University, College of Medicine, Saudi Arabia
}

\begin{abstract}
Introduction: Sleep is an essential element of good health. It is one of the most basic physiological needs of human beings. Its quality is strongly related to psychological and physical health and other measures of well-being [1]. The pattern of adequate sleep and wakefulness in different subjects is known to vary with people's age, the demands of their occupation, their physiological and psychosocial characteristics, psychiatric illness, and some types of physical illness. Aim of the Study: The aim of this study is to describe sleep and habits, and to investigate the relationships between sleep habits sleep quality and the academic performance among Saudi medical students in eastern province, Saudi Arabia. Sleep habits can lead to progressively later sleep and wake times, missed classes, poor academic performance, and chronic sleep difficulties. Results: More than one-half (57.6\%) of the students are having an income of up to 990 SR/month. And about one-eighth (14.2\%) of the students have a part-time job besides studying. Most of the students were found to be healthy and 28 students stated that they have a chronic disease, out of whom, 14 were excluded from the study as follows, 5 due to sickle cell anemia, 4 were having hypertension, 1 was having gastro-esophageal reflux disease, and 5 bronchial asthma patients. Conclusion: These data do tell us whether individuals are likely to practice a certain behaviour and whether it is associated with poor sleep quality. It provides an estimate of the potential impact these behaviours may have in the student's community. This study have shown a similar total sleep time ( 6.45 hours) and comparable sleep latency (28.2 mins) to many studies done on college students all over the world. In general, this study shows that in the most part.
\end{abstract}

Keywords: sleeping habits, medical students, academic performance

\section{Introduction}

Sleep is an essential element of good health. It is one of the most basic physiological needs of human beings. Its quality is strongly related to psychological and physical health and other measures of well-being [1].

The pattern of adequate sleep and wakefulness in different subjects is known to vary with people's age, the demands of their occupation, their physiological and psychosocial characteristics, psychiatric illness, and some types of physical illness. [2]

It has been postulated that inadequate sleep is associated with numerous adverse effects, one of which is impaired academic performance. Recent reviews have indicated an important relationship between sleep patterns with learning abilities and consequent academic performance [3].

\section{Aim of the Study}

The aim of this study is to describe sleep and habits, and to investigate the relationships between sleep habits sleep quality and the academic performance among Saudi medical students in eastern province, Saudi Arabia. Sleep habits can lead to progressively later sleep and wake times, missed classes, poor academic performance, and chronic sleep difficulties.[10].
Sleep, memory and academic performance.

Of specific interest in this field is learning theory. Sleep is suggested to play a significant role in consolidating learning and memory; this has been shown in many studies [27]. In view of that, retention of new information may in fact be dependent on activating "...some brain function that occurs at a critical period after the registration of this information" [19].

Study Design: This is Cross-sectional study through selfadministered questionnaire.

Statistical Analysis: Statistical analysis was performed using SPSS program $21^{\text {st }}$ version. Descriptive analysis was presented in form of tables and graphs. The mean frequency (number of days per week) of sleep habit was calculated. The mean represent the number of days/week in which the participants engaged in a particular behavior. Frequency scores are calculated for each item, and higher frequency scores indicate worse sleep habit

Analysis of variance (ANOVA) and t-test were used to test significance between continuous variables, while a Chisquare test was used to test independency between categorical data. In this study, a p-value of less than 0.05 was considered as significant in all the tests. 


\section{International Journal of Science and Research (IJSR) \\ ISSN (Online): 2319-7064}

Index Copernicus Value (2013): 6.14 | Impact Factor (2015): 6.391

\section{Results}

More than one-half $(57.6 \%)$ of the students are having an income of up to $990 \mathrm{SR} / \mathrm{month}$. And about one-eighth $(14.2 \%)$ of the students have a part-time job besides studying (figure 1). Most of the students were found to be healthy and 28 students stated that they have a chronic disease, out of whom, 14 were excluded from the study as follows, 5 due to sickle cell anemia, 4 were having hypertension, 1 was having gastro-esophageal reflux disease, and 5 bronchial asthma patients.

\section{Descriptive statistics of sleep quality, total sleep time (TST) and sleep latency}

Sleep quality: Over one half of our sample $(53.6 \% ; \mathrm{n}=177)$ met the clinical cutoff of the Pittsburgh Sleep Quality Index (PSQI) for poor sleep quality (table 8). However, using a higher cut point in our analysis, about two-fifth $(\mathrm{N}=95$, $28.8 \%$ ) of the students were having a PSQI total score $>7$. Out of the 356 participants, 82 were having a PSQI score of 6 or 7 and considered indeterminate and were excluded from the association's analysis. Also 26 students were excluded because of incomplete data.

Total sleep time and sleep latency: The studied sample's total sleep time was found to be $6.45 \pm 1.26$ (mean \pm SD) hours with sleep latency (time needed to fall asleep) to be $28.19 \pm 20.814$ (mean \pm SD) minutes

Sleep quality and association with studying habits: Univariate analysis of length of studying hours/ day during the week days and the weekends showed a statistically significant difference among good and poor sleepers ( $\mathrm{p}$ value $<0.001$ and 0.016 respectively). As shown in (figure 2, figure 3), it was found that a linear relationship exists in which good sleep quality is more common among those who study up to 2 hours/day and trends down with those who study less than or more than 2 hours/day.

\section{studying hours in the week days and its association with sleep qualitypoor sleep}

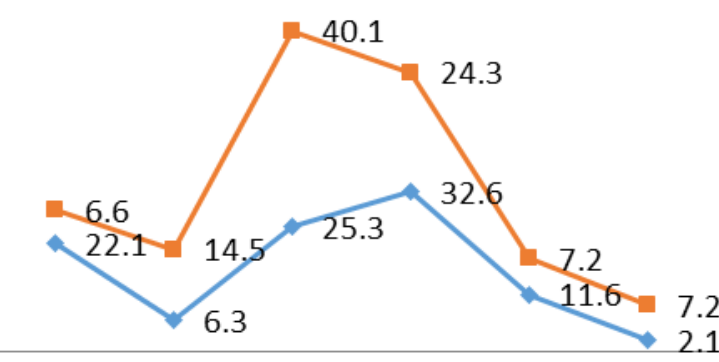

Less 1 hours up to 2 up to up to 4 more than 1 hrs 3hrs hrs than 4 hrs hrs

Figure 1: Studying hours in the week days and its association with sleep quality

\section{Sleep quality and association with School attendance}

A statistically significant difference was found in school attendance among good and poor sleepers. More than half $(\mathrm{N}=137,53.3 \%)$ of the students reported missing classes in the last month. Moreover, about one-half $(\mathrm{N}=126,49.2 \%)$ of the students are missing classes because of inadequate sleep and sleep disturbance. It was noted that about two-thirds $(67.3 \%)$ of the poor sleepers are missing classes because of sleep disturbance in comparison with $37.4 \%$ in the good sleeper group $(\mathrm{p}<0.001)$.

Table 1: Sleep quality and association with school attendance

\begin{tabular}{|c|c|c|c|c|}
\hline & total & $\begin{array}{c}\text { Poor sleep } \\
\text { quality } \\
\mathrm{N}(\%)\end{array}$ & $\begin{array}{c}\text { Good sleep } \\
\text { quality } \\
\mathrm{N}(\%)\end{array}$ & P value \\
\hline \multicolumn{5}{|c|}{ Missed classes in the last month } \\
\hline No & 117 & $27(23.1)$ & $90(76.9)$ & $<0.001$ \\
\hline Yes & 131 & $68(51.9)$ & $63(48.1)$ & \\
\hline Missed classes because of inadequate sleep \\
\hline No & 125 & $30(24.0)$ & $95(76.0)$ & $<0.001$ \\
\cline { 1 - 4 } Yes & 122 & $65(53.3)$ & $57(46.7)$ & \\
\hline
\end{tabular}

Sleep quality and academic performance:

Out of 356 included questionnaires, 278 (78.1\%) have declared their Grade point average (GPA). The mean of the GPAs were $3.82 \pm 0.60$ (mean \pm SD). The study didn't observe any correlation between sleep quality and GPA among the studied population.

\section{Discussion}

Sleep is one of the important needs; a need that plays a significant role in human's life quality and their activities when they are awake. It is a major factor associated with the physical and mental health of individuals.

The present study aims to determine the prevalence of inadequate sleep and poor sleep quality and to examine the relationships of different domains of sleep habit with sleep quality and academic performance among medical students. Additionally, socioeconomic status was examined for differences in sleep quality.

The sample for the current study consisted of primarily single males, Saudi nationals, in their early 20's who are attending school full-time and some of whom (14.2\%) had a part-time occupation.

\section{Sleep quality and association with academic performance:}

This study didn't find any correlation between sleep quality and student's GPA. This finding doesn't go in line with Curcio et al. (2006) [3], BaHammam et al. (2012) [11], and Taylor et al. (2013) [16]. This inconsistency can be explained by limitations of survey design and self-report data, which are subjected to several sources of error including recall and social desirability leading to either overor under-reporting. In this study, the mean of the GPAs were $3.82 \pm 0.60($ mean $\pm \mathrm{SD})$ which is notably high and could be 


\section{International Journal of Science and Research (IJSR) \\ ISSN (Online): 2319-7064}

Index Copernicus Value (2013): 6.14 | Impact Factor (2015): 6.391

affected by social desirability. Also, about three-quarters $(\mathrm{N}=286,77.3 \%)$ of students have stated their GPA and out of whom, only $216(75.5 \%)$ were eligible for the analysis.

\section{Conclusion}

These data do tell us whether individuals are likely to practice a certain behavior and whether it is associated with poor sleep quality. It provides an estimate of the potential impact these behaviors may have in the student's community.

This study have shown a similar total sleep time ( 6.45 hours) and comparable sleep latency (28.2 mins) to many studies done on college students all over the world.In general.

Activities that increase arousal at bedtime, and improper sleep environmental conditions particularly increased cognitive activity at bedtime, performing activities requiring high level of concentration near bedtime, use of uncomfortable mattress, poor room temperature control and increased noise at bedtime are associated with poor sleep quality. The data also shows the high prevalence of poor sleep quality among medical students, with $53.6 \%(n=177)$ have met the clinical cut off of PSQI for poor sleep quality (PSQI $\geq 6$ )

\section{References}

[1] Pilcher JJ, Ott ES. The relationships between sleep and measures of health and well-being in college students: A repeated measures approach. Behav Med. 1998;23:1707.

[2] Tsui YY, Wing YK. A study on the sleep patterns and problems of university business students in Hong Kong. J Am Coll Health. 2009;58:1 67-76.

[3] Curcio G, Ferrara M, De Gennaro L. Sleep loss, learning capacity and academic performance. Sleep medicine reviews. 2006;10(5):323-37.

[4] Kang JH, Chen SC. Effects of an irregular bedtime schedule on sleep quality, daytime sleepiness, and fatigue among university students in Taiwan. BMC Public Health. 2009 Jul 19;9:248. doi: 10.1186/14712458-9-248.

[5] MONIQUE K. LeBOURGEOIS, FLAVIA GIANNOTTI, [...], and JOHN HARSH Sleep Habit and Sleep Quality in Italian and American Adolescents. Ann N Y Acad Sci. Author manuscript; available in PMC Nov 16, 2010. Published in final edited form as: Ann N Y Acad Sci. Jun 2004; 1021: 352-354. doi: 10.1196/annals.1308.044

[6] American Academy of Sleep Medicine (AASM), International classification of sleep disorders. 2. Westchester, IL: Author; 2001

[7] Stuart F. Quan, Janis L. Anderson, Gordon K. Hodge.Use of a Supplementary Internet Based Education Program Improves Sleep Literacy in College Psychology Students. J Clin Sleep Med. 2013 February 1; 9(2): 155-160. doi: 10.5664/jcsm.2414
[8] Buboltz WC, Jr, Brown F, Soper B. Sleep habits and patterns of college students: a preliminary study. J Am Coll Health. 2001;50:131-5.

[9] Forquer LM, Camden AE, Gabriau KM, Johnson CM. Sleep patterns of college students at a public university. J Am Coll Health. 2008;56:563-5.

[10]Lack LC. Delayed sleep and sleep loss in university students. J Am Coll Health. 1986;35:105-10.

[11] Epstein, L.J. \& Mardon, S. The Harvard Medical School Guide to a Good Night's Sleep. McGraw Hill, New York. (2007).

[12] Lisa Matricciani, Sarah Blunden, Gabrielle Rigney, Marie T. Williams, Tim S. Olds. Children's Sleep Needs: Is There Sufficient Evidence to Recommend Optimal Sleep for Children? Sleep. 2013 April 1; 36(4): 527-534. doi: 10.5665/sleep. 2538

[13] Wolfson A, Carskadon M. Sleep schedules and daytime functioning in adolescents. Child Devel. 1998;69:8 7587.

[14] Steenari M, Vuontela V, Paavonen J, Carlson S, Fjällberg M, Aronen E. Working memory and sleep in 6-to 13-year-old schoolchildren. J Am Acad Child Adolesc Psychiatry.2003;42:85-92.

[15] Gruber R, Laviolette R, Deluca P, Monson E, Cornish $\mathrm{K}$, Carrier J. Short sleep duration is associated with poor performance on IQ measures in healthy school-age children. Sleep Med. 2010;11:2 89-94.

[16] Blunden S, Chervin R. Sleep problems are associated with poor outcomes in remedial teaching programs. J Paediatr Child Health. 2007;44:2 37-42.

[17] Cappuccio F, Taggart F, Kandala N, et al. Meta-analysis of short sleep duration and obesity in children and adults. Sleep. 2008;31:6 19-26.

[18] Sanjay R. Patel, Frank B. Hu Short sleep duration and weight gain: a systematic review. Obesity.2008;16:6 4353.

[19] Lin J, Tung H, Hsieh Y, Lin F. Interactive effects of delayed bedtime and family-associated factors on depression in elementary school children. Res Devel Dis.2011;32:20 36-44

[20] Koulouglioti C, Cole R, Kitzman H. Inadequate sleep and unintentional injuries in young children. Public Health Nursing. 2008;25:10 6-14.

[21] Lam L, Yang L. Short duration of sleep and unintentional injuries among adolescents in China. Am J Epidemiol. 2007;166:1053-8.

[22] Li Y, Jin H, Owens $\mathrm{J}, \mathrm{Hu} \mathrm{C}$. The association between sleep and injury among school-aged children in rural China: a case-control study. Sleep Med. 2008;9:142-8.

[23] Welstein L, Dement WC, Redington D, Guilleminault C, Mitler MM. Insomnia in the san francisco by area: A Telephone Survey. In: Guilleminault C, Lugaresi E, editors. Sleep/Wake Disorders: Natural History, Epidemiology, and Long-Term Evaluation. New York: Raven Press; 1983. pp. 73-85.

[24] Mellinger GD, Balter MB, Uhlenhuth EH. Insomnia and its treatment. Prevalence and correlates. Arch Gen Psychiatry. 1985;42:225-32.

[25] Forquer LM, Camden AE, Gabriau KM, Johnson CM. Sleep patterns of college students at a public university. J Am Coll Health. 2008;56:563-5. 
[26] Harsora P, Kessmann j, Nonpharmacologic Management of Chronic Insomnia. Am Fam Physician. 2009 Jan 15;79(2):125-130.

[27] Brown FC, Buboltz WC Jr, Soper B. Development and evaluation of the Sleep Treatment and Education Program for Students (STEPS). J Am Coll Health. 2006 Jan-Feb;54(4):231-7. 